\title{
Influence of Erbium Ions on the Optical and Structural Properties of Polyvinyl Alcohol
}

\author{
Taymour A. Hamdalla, ${ }^{1,2}$ Taha A. Hanafy, ${ }^{1,3}$ and Ashraf E. Bekheet ${ }^{1,4}$ \\ ${ }^{1}$ Physics Department, Faculty of Science, University of Tabuk, Tabuk 71451, Saudi Arabia \\ ${ }^{2}$ Physics Department, Faculty of Science, University of Alexandria, Alexandria 21934, Egypt \\ ${ }^{3}$ Physics Department, Faculty of Science, Fayoum University, Fayoum 63514, Egypt \\ ${ }^{4}$ Physics Department, Faculty of Education, Ain Shams University, Cairo 21974, Egypt
}

Correspondence should be addressed to Taymour A. Hamdalla; taymour_76@yahoo.com

Received 10 December 2014; Revised 29 April 2015; Accepted 11 May 2015

Academic Editor: Austin Nevin

Copyright (C) 2015 Taymour A. Hamdalla et al. This is an open access article distributed under the Creative Commons Attribution License, which permits unrestricted use, distribution, and reproduction in any medium, provided the original work is properly cited.

Polyvinyl alcohol (PVA) films doped with erbium chloride $\left(\mathrm{ErCl}_{3}\right)$ have been prepared by casting from their aqueous solutions. The structure of the doped samples as well as the interactions between the host PVA and $\mathrm{Er}^{+3}$ was investigated using FTIR spectroscopy. The optical measurement was recorded at room temperature in the range from $200 \mathrm{~nm}$ to $2000 \mathrm{~nm}$. FTIR measurements revealed that $\mathrm{Er}^{+3}$ forms complex configuration within the PVA structure. PVA doped with $9 \mathrm{wt} \%$ of $\mathrm{ErCl}_{3}$ exhibits energy gap and refractive index of $5.1 \mathrm{eV}$ and 1.72, respectively. The effect of the doping increment of $\mathrm{ErCl}_{3}$ on the optical parameters has been discussed.

\section{Introduction}

Rare earth doped polymers are being widely used for many technological and biological applications. They have been greatly stimulated by their potential use as biosensors, bioprobes, electroluminescent displays, LED diodes, and lasers $[1,2]$. Many attempts are being made to dope rare earth ions in polymeric materials and study their structural, dielectric, and optical properties. PVA is a semicrystalline polymer and its crystalline index depends on the synthetic process and physical aging [3,4]. PVA is also a nontoxic and water soluble polymer. It has a strong film forming ability with very high dielectric strength, good charge storage capacity, high mechanical tensile strength, and optical properties $[5,6]$. Doping of transition metal salts into permanently polarized vinyl polymers like PVA in a multiphase system can induce pronounced changes in various properties of complexes [7]. It is reported that $\mathrm{Nd}, \mathrm{Sm}, \mathrm{Gd}$, and $\mathrm{Er}$ are monohydroxides which can form hydroxo complexes within the polymer solution [8]. The hydroxyl $(\mathrm{OH})$ groups of PVA are attached to every second carbon atom in the carbon backbone of the long chain molecule. Hydroxyl functional groups can form complexes with the lanthanides cations into their polymer network structure [9]. Rare earth complexes were integrated into polymer matrix with van der Waals force or weak static effects [10].

These complexes can be expected to exhibit more effective properties because each dispersed complex molecule is a luminescent unit. So the transparency interfacial interactions between the rare earth luminescent species and the polymer matrix are primary factors determining the total luminescent behavior of the rare earth polymer composites [11]. The most suitable molecular structures of the rare earth polymer complexes are shown in Figure 1. The refractive index of PVA is very useful in optics and photonics due to their ability to increase the light output and also reduce reflection loss [12]. The permanently polarized vinyl polymer will have various changes in its properties when it is doped with a rare earth salt like $\mathrm{ErCl}_{3}[13,14]$.

Moreover, rare earth salts have considerable effect on the structural, optical, and thermal properties of many types of polymer [15]. $\mathrm{Er}^{+3}$ doped material has attracted a lot of research interest due to its significant optical properties. In its trivalent state, at a wavelength of $1.52 \mu \mathrm{m}$, it exhibits 


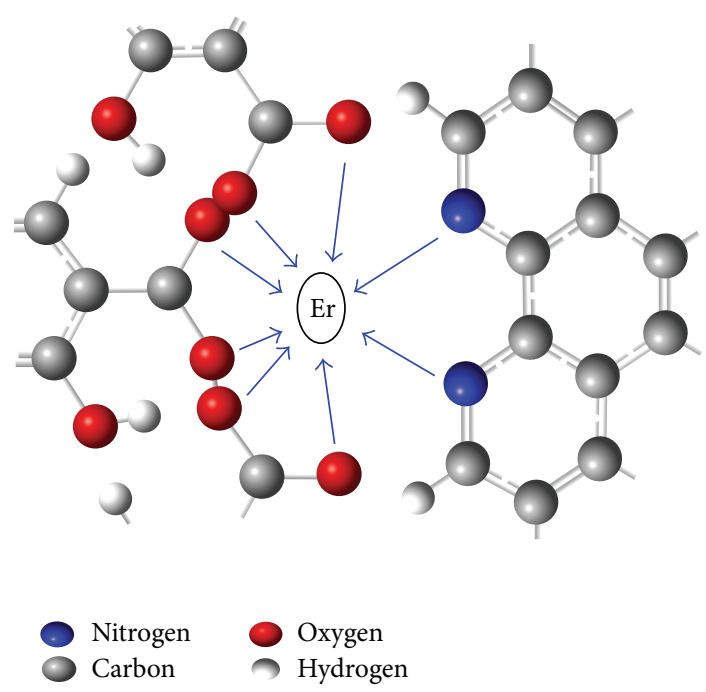

FIGURE 1: Molecular structure of Er-polymer complexes.

a transition from its first excite state ${ }^{4} \mathrm{I}_{13 / 2}$ to the ground state ${ }^{4} \mathrm{I}_{15 / 2}$ [16]. When $\mathrm{Er}^{+3}$ is mixed with a host solid material, it induces mixing of states. These states will lead to new transitions due to the fact that the partially filled $4 \mathrm{f}$ shell is shielded by filled $5 \mathrm{~s}$ and $5 \mathrm{p}$ shell [17].

In this paper, we have synthesized $\mathrm{ErCl}_{3}(1,3,5,7$, or $9 \% \mathrm{wt}$ ) doped PVA polymers films. The effect of $\mathrm{Er}^{+3}$ ion concentration on the optical properties of PVA sample is investigated.

\section{Theoretical Concept}

To calculate the energy band gap $\left(E_{g}\right)$ of the PVA samples, first the absorption coefficient $(\alpha)$ can be determined by

$$
\alpha=\frac{1}{x} \ln \left(\frac{1-R}{T}\right),
$$

where $x$ is the sample thickness and $R$ and $T$ are the measured reflectance and transmittance, respectively. Then, the absorption constant $k$ is given by $k=\lambda \alpha / 4 \pi$, where $\lambda$ is the wavelength.

The refractive index $n$ plays a vital role in the optical properties and it follows that [18]

$$
n=\frac{(1+R)+\sqrt{4 R-(1-R)^{2} k}}{(1-R)} .
$$

To calculate the optical dispersion parameters, single oscillator energy $\left(E_{s}\right)$, and dispersion energy $\left(E_{d}\right)$, we use the proposed model of Wemple and DiDomenico (WDD) [19]. The refractive index is calculated using the single effective oscillator equation:

$$
n^{2}-1=\frac{E_{d} E_{s}}{E_{s}^{2}-(h \nu)^{2}},
$$

where $E_{s}$ is the single oscillator energy and $E_{d}$ is the dispersion energy.
The optical parameters such as the refractive index $\left(n_{\infty}\right)$ at long wavelengths, the average interband oscillator wavelength $\left(\lambda_{o}\right)$, and the average oscillator strength $\left(S_{o}\right)$ are given by [20]

$$
n^{2}-1=\frac{S_{o} \lambda_{o}^{2}}{1-\left(\lambda_{o}^{2} / \lambda^{2}\right)} .
$$

Equation (4) can be rearranged as

$$
\frac{1}{n^{2}-1}=\frac{1}{S_{o} \lambda_{o}^{2}}-\frac{1}{S_{o} \lambda^{2}} .
$$

By plotting the relation between $1 / n^{2}-1$ and $1 / \lambda^{2}$, the slope of the straight line will be $-1 / S_{o}$, while the intersection will be $1 / S_{o} \lambda_{o}$.

Finally, the refractive index $n_{\infty}$ at long wavelengths follows the relation

$$
S_{o}=n_{\infty}^{2}-\frac{1}{\lambda_{o}^{2}}
$$

\section{Experimental Techniques}

PVA material is obtained from Avondale Laboratories (Banbury, Oxon, England); it has an average molecular weight of $17000 \mathrm{~g} / \mathrm{mole}$. Erbium chloride was obtained from SigmaAldrich (Steinheim, Germany). At $80^{\circ} \mathrm{C}$ with continuous stirring, PVA powder was dissolved in triple distilled water. We maintain the solution at $80^{\circ} \mathrm{C}$ for $30 \mathrm{~min}$ until a clear solution is obtained. At $50^{\circ} \mathrm{C}$ with continuous stirring, the solution was cooled slowly. $\mathrm{ErCl}_{3}$ with different concentrations $(1,3,5$, 7 , or $9 \% \mathrm{wt}$ ) was dissolved in $0.5-1 \mathrm{~mL}$ of concentrated $\mathrm{HCl}$.

By addition of $10 \mathrm{~mL}$ of triple distilled water at $50^{\circ} \mathrm{C}$, the mixture was diluted with continuous stirring. Then, the mixture was added to the PVA solution at $50^{\circ} \mathrm{C}$ with continuous stirring of the final mixture for $12 \mathrm{~h}$. The aqueous solution of the mixture was cast into a Petri dish placed on a leveled plate at $35^{\circ} \mathrm{C}$ for 7 days until the solvent was completely evaporated. The obtained polymer film has $0.08 \mathrm{~mm}$ thickness. The optical transmittance and reflectance of the PVA samples have been measured by using a UV-Vis spectrophotometer model V-670 JASCO in the wavelength range of 200-2000 $\mathrm{nm}$. Fourier transform infrared (FTIR) spectra of pure PVA and that doped with 1, 3, 5, 7, or $9 \mathrm{wt} \%$ of $\mathrm{ErCl}_{3}$ were measured using IRPrestige-21 (Shimadzu, Japan). The FTIR spectral wavelength used is in the range from $400 \mathrm{~cm}^{-1}$ to $4000 \mathrm{~cm}^{-1}$. The resolution for measuring the optical absorbance is $0.5 \mathrm{~cm}^{-1}$.

\section{Results and Discussion}

4.1. FTIR Analysis. Infrared spectroscopy is used to identify the interaction of polymer with filler material. It was found that FTIR spectroscopy is very sensitive to the formation of the hydrogen bond [20]. Figure 2 shows FTIR optical absorbance spectra for pure PVA, while Figures 3(a)-3(e) illustrate FTIR for PVA doped with 1, 3, 5, 7, or 9 wt $\%$ of $\mathrm{ErCl}_{3}$. It is observed that pure PVA undergoes strong bands 


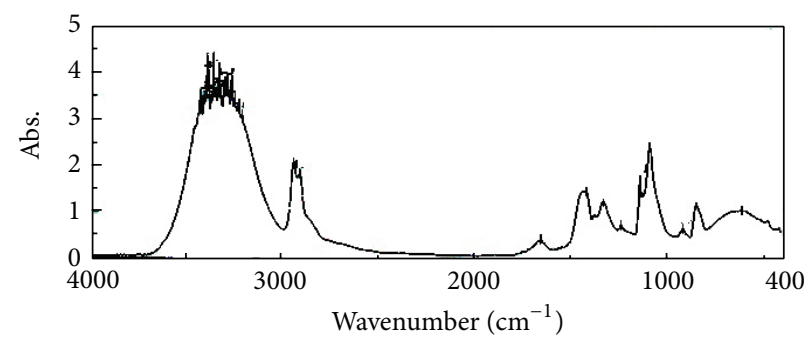

FIgURE 2: Absorption spectra of pure PVA obtained from FTIR in the range $4000-400 \mathrm{~cm}^{-1}$ recorded at room temperature. The peaks show the resonance wavenumber of pure PVA.

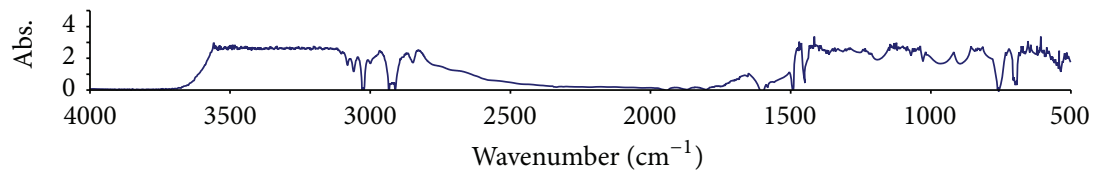

(a)

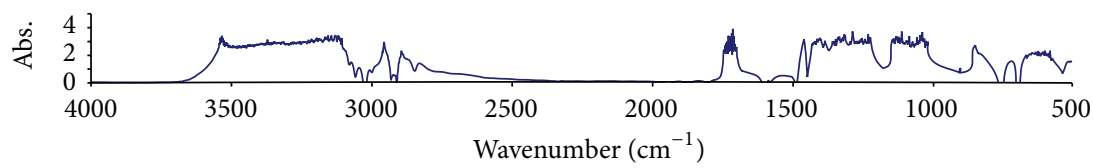

(b)

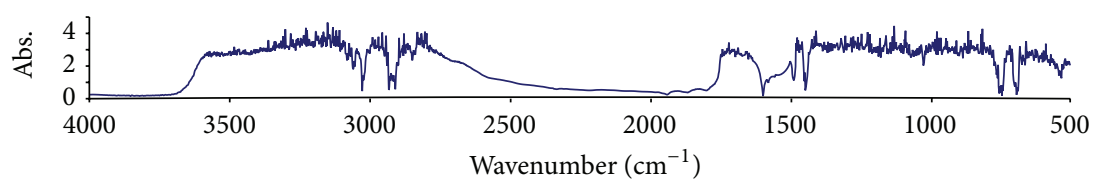

(c)

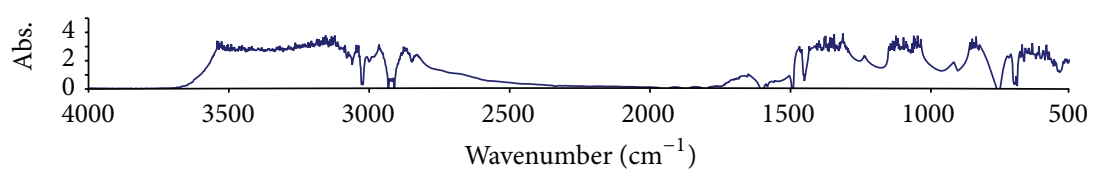

(d)

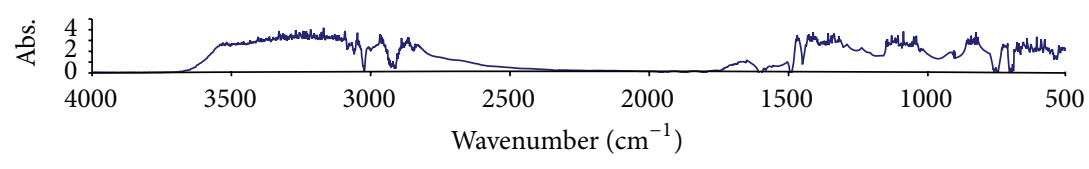

(e)

FIGURE 3: (a-e) Absorption spectra of pure PVA obtained from FTIR for PVA doped with $\mathrm{ErCl}_{3}$ of concentrations 1, 3, 5, 7, or 9 wt\%, respectively.

at $3430-3244 \mathrm{~cm}^{-1}$. This band is attributed to $\mathrm{OH}$ stretching vibration of $\mathrm{OH}$ groups of PVA structure. The bands at $2941 \mathrm{~cm}^{-1}$ and $2855 \mathrm{~cm}^{-1}$ correspond to asymmetric and symmetric stretching vibration of $\mathrm{C}-\mathrm{H}$ bond of PVA main chain, respectively. The band corresponding to stretching vibration of the carbonyl groups $\mathrm{C}=\mathrm{O}$ of PVA ester occurs at $1735 \mathrm{~cm}^{-1}$. The band at $1568 \mathrm{~cm}^{-1}$ is assigned to O$\mathrm{H}$ and $\mathrm{C}-\mathrm{H}$ bending vibrations. The bending wagging of $\mathrm{CH}_{2}$ vibrations is observed at $1433 \mathrm{~cm}^{-1}$ and $1375 \mathrm{~cm}^{-1}$, respectively. Also, $\mathrm{C}-\mathrm{H}$ wagging is obtained at $1256 \mathrm{~cm}^{-1}$. The band at about $1095 \mathrm{~cm}^{-1}$ is due to $\mathrm{C}-\mathrm{O}$ stretching of acetyl groups of PVA and the band which is observed at $945 \mathrm{~cm}^{-1}$ is assigned to $\mathrm{C}-\mathrm{O}$ symmetric stretching.

From Figures 3(a)-3(e) it is clear that FTIR bands for lanthanides chlorides doped PVA are not modified drastically. However, it can be observed that the intensity of the peak of $\mathrm{C}=\mathrm{O}$ band $\left(1735 \mathrm{~cm}^{-1}\right)$ is increased with the increase in $\mathrm{ErCl}_{3}$ within PVA structure from $1 \mathrm{wt} \%$ up to $5 \mathrm{wt} \%$. This can be attributed to the formation of new carbonyl groups within the doped PVA samples. These groups $(\mathrm{C}=\mathrm{O})$ are responsible for the degradation and the increase in the amorphous phases within the investigated PVA samples. 


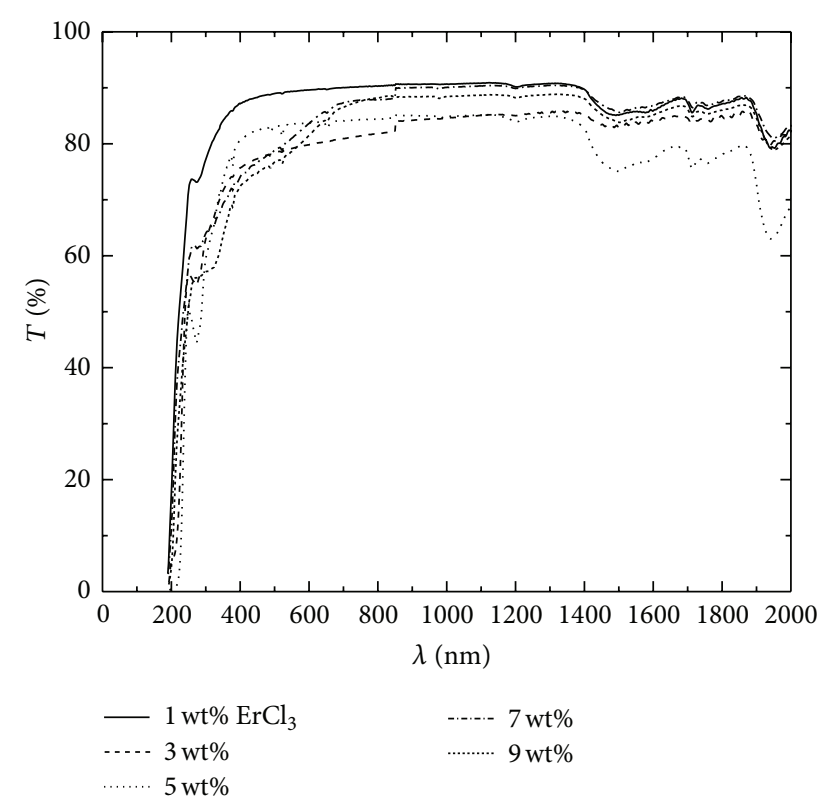

FIGURE 4: Transmission spectra for PVA contain different doping concentrations of $\mathrm{ErCl}_{3}$.

In addition, the observed band of $\mathrm{O}-\mathrm{H}$ groups at 3430$3244 \mathrm{~cm}^{-1}$ exhibits a decrease in the intensity for all doped PVA samples. So the decrease in the intensity of this band indicates that there is a decrease in the number of free $\mathrm{OH}$ groups of the PVA main chain. This can be attributed to the complexes formation between $\mathrm{Er}^{+3}$ ions with $\mathrm{OH}$ groups of PVA skeleton [21]. Consequently, it can be concluded that the presence of $\mathrm{Er}^{+3}$ ions within PVA sample leads to the main chain degradation and the increase of the amorphous phases within the investigated sample. So the decrease in the hydrogen bonds along the PVA main chain can be expected.

4.2. Optical Properties Analysis. Figure 4 shows the optical transmission variation versus the wavelength from $200 \mathrm{~nm}$ to $2000 \mathrm{~nm}$. Different doping ratio of $\mathrm{ErCl}_{3}(1,3,5$, 7, or 9 wt\%) within PVA has been considered. The transmission of the PVA samples decreased by the increase in the doping ratio of $\mathrm{ErCl}_{3}$ within the PVA samples. The decrease in the transmission of all doped PVA samples with the increase in $\mathrm{ErCl}_{3}$ concentration can be assigned to the increase of the disorder within the polymeric samples. It was previously reported that rare earth ions within the polymer structure decrease the ordering character in the crystalline phases of PVA as well as polyvinylidene fluoride (PVFD) [13]. This is due to the complexes formation between rare earth ions and cations of the polymer main chain.

Several reports confirmed that the optical absorption of PVA sample is increased with the increase in $\mathrm{Eu}^{+3}, \mathrm{Sm}^{+3}$, and $\mathrm{Ce}^{+3}$ within PVA structure $[13,22,23]$. This is due to the presence of the amorphous phases that is constructed by the interaction between these ions and $\mathrm{OH}$ groups of PVA samples. Consequently, the decrease in the optical transmission of PVA with the increase in the doping ratio of $\mathrm{Er}^{+3}$ within PVA structure is expected. The presence of

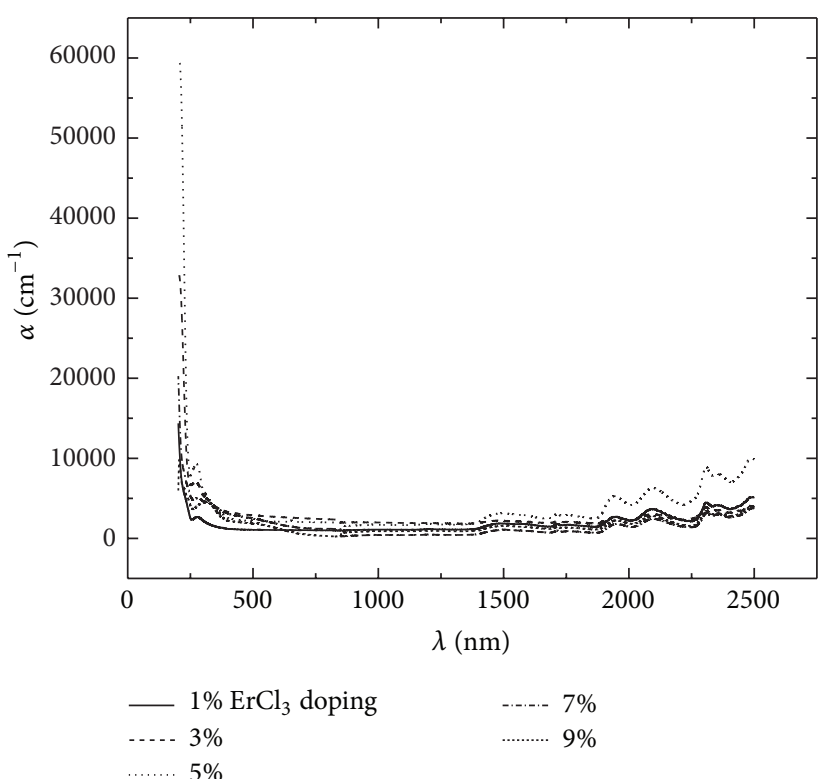

FIGURE 5: Absorbance of the wavelength for PVA contains different doping concentrations of $\mathrm{ErCl}_{3}$.

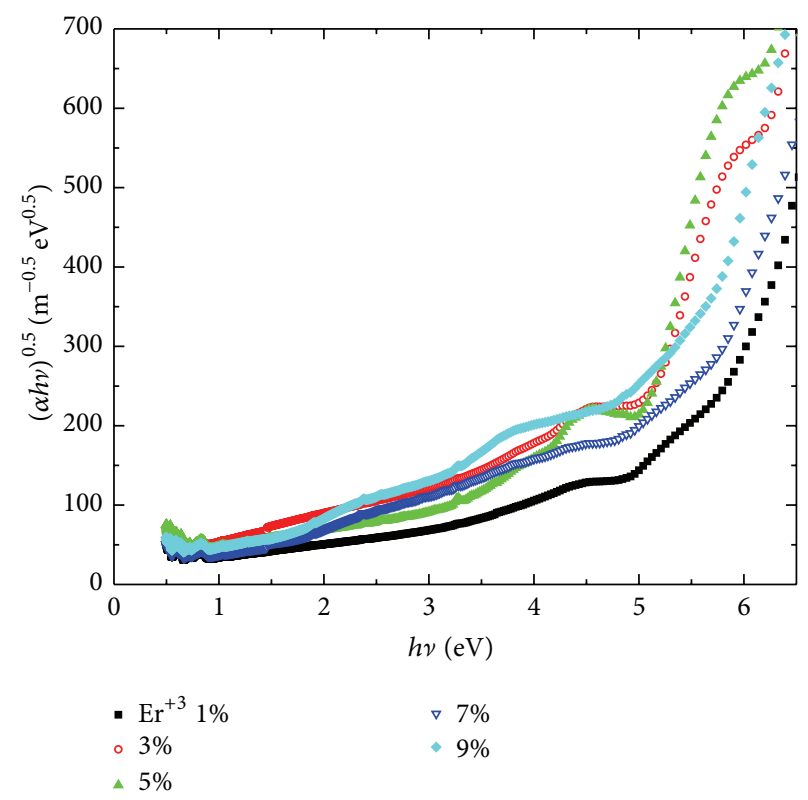

FIgURE 6: The plot of $(\alpha h \nu)^{0.5}$ versus $h \nu$ for PVA : $\mathrm{ErCl}_{3}$.

these complexes decreases the free hydrogen bonds of the main chain of the doped PVA samples. Consequently, it is suggested that the decrease in the hydrogen bonds may lead to the decrease in the transmission of all the PVA samples. Figure 5 displays the relation between the absorbance of the PVA with different $\mathrm{ErCl}_{3}$ concentrations mentioned above and the wavelength. It is found that the absorption coefficient will increase by the increment of the filler concentration.

Figure 6 depicts the relation between $(\alpha h \nu)^{0.5}$ and photon energy $(h v)$. The relation governing the straight line partition in the curve is $(\alpha h \nu)^{0.5}=A\left(h \nu-E_{g}^{\text {opt }}\right)$, where $A$ is 
TABLE 1: The optical parameters for PVA doped with different concentration of $\mathrm{ErCl}_{3}$.

\begin{tabular}{|c|c|c|c|c|c|}
\hline & $\mathrm{PVA} / \mathrm{ErCl}_{3}$ wt $1 \%$ & Wt $3 \%$ & Wt $5 \%$ & Wt 7\% & Wt $9 \%$ \\
\hline$E_{s}(\mathrm{eV})$ & 2.25 & 1.96 & 1.63 & 1.52 & 1.48 \\
\hline$E_{d}(\mathrm{eV})$ & 1.30 & 1.50 & 1.82 & 2.10 & 2.60 \\
\hline$S_{o}\left(10^{-7} \mathrm{~nm}^{-2}\right)$ & 26.00 & 51.00 & 62.00 & 69.00 & 74.00 \\
\hline$n_{\infty}$ & 1.40 & 1.43 & 1.50 & 1.52 & 1.59 \\
\hline$\lambda_{o}(\mathrm{~nm})$ & 296.00 & 330.00 & 338.00 & 442.00 & 519.00 \\
\hline
\end{tabular}

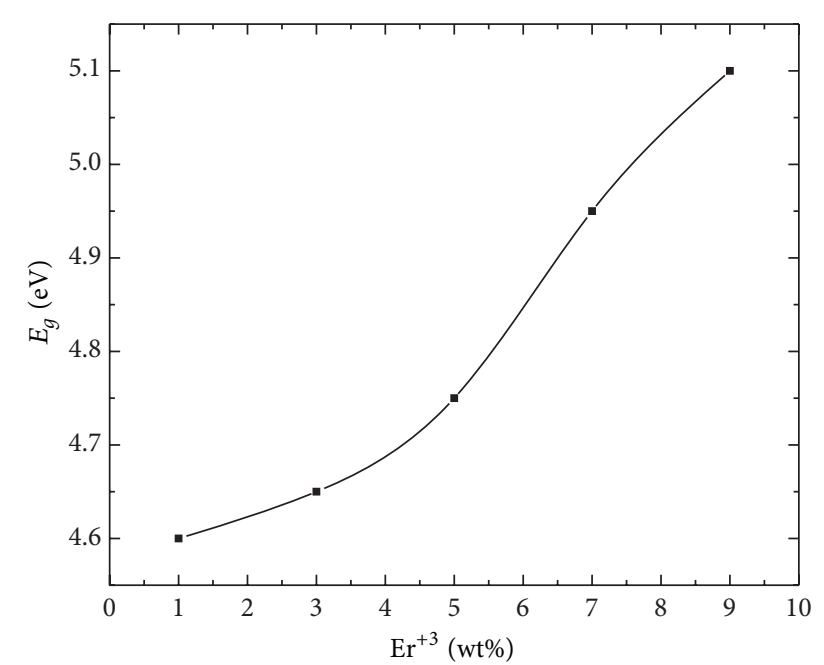

FIGURE 7: Energy gap variation in $\mathrm{eV}$ with the doping concentrations of $\mathrm{ErCl}_{3}$ within PVA samples.

a constant. So the extrapolation to the abscissa yields to the corresponding forbidden band width energy $\left(E_{g}\right)$. The slope of the straight line gives us the constant $A$. The values of $A$ are scheduled in Table 1 and they increase with the increase of $\mathrm{ErCl}_{3}$. Figure 7 shows the relation between the energy gap of PVA samples and the $\mathrm{ErCl}_{3}$ doping concentrations. It is indicated that the energy gap increases with the increase of $\mathrm{ErCl}_{3}$ doping. The increment of $E_{g}$ for all doped PVA samples can be discussed as follows. The increase of $\mathrm{ErCl}_{3}$ ratio within the skeleton of PVA leads to the decrease in the intensity of the $\mathrm{OH}$ groups of the main PVA chains. This is due to the formation of noncovalent bonds between $\mathrm{Er}^{+3}$ and $\mathrm{OH}$ groups of the PVA backbone.

Figure 8 shows the relation between the refractive index (n) of PVA samples and wavelength. The refractive index dispersion is a significant factor in optical communication and in designing devices for spectral dispersion. It is clear that the increase in doping ratio of $\mathrm{ErCl}_{3}$ inside the PVA samples will increase the refractive index of PVA. The maximum value of refractive index (1.72) was achieved for the PVA samples containing $9 \mathrm{wt} \%$ of $\mathrm{ErCl}_{3}$ at $1000 \mathrm{~nm}$. This can be attributed to the highest electronegative value of $\operatorname{Er}(1.24 \mathrm{eV})$ [24]. As a result, $\mathrm{Er}^{+3}$ ions can form metal-legend complexes inside the polymer matrix. These complexes can be bounded via coordination and ionic bonds with $\mathrm{OH}$ groups of the next layer of PVA. Consequently, $\mathrm{Er}^{+3}$ ions act as structure

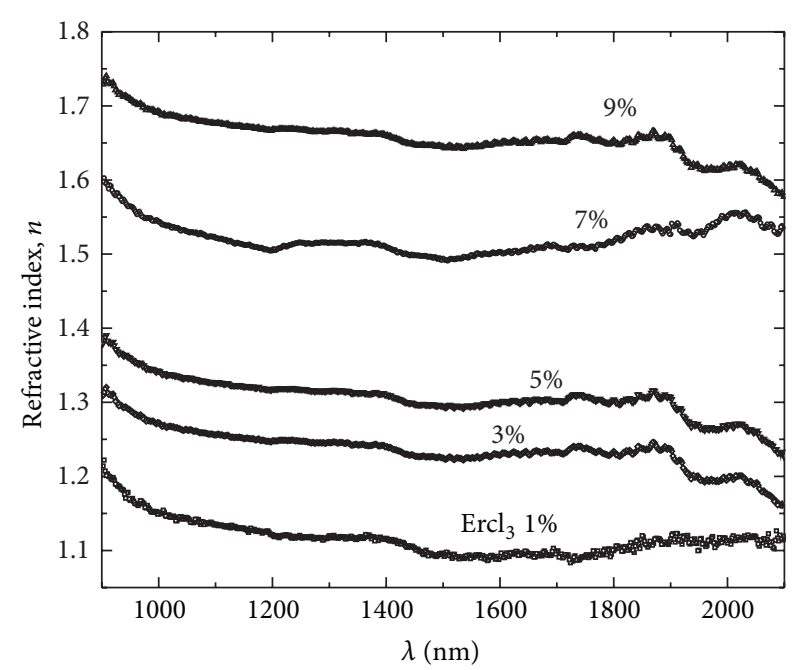

FIGURE 8: Relation between the refractive index and the wavelength for PVA : $\mathrm{ErCl}_{3}$.

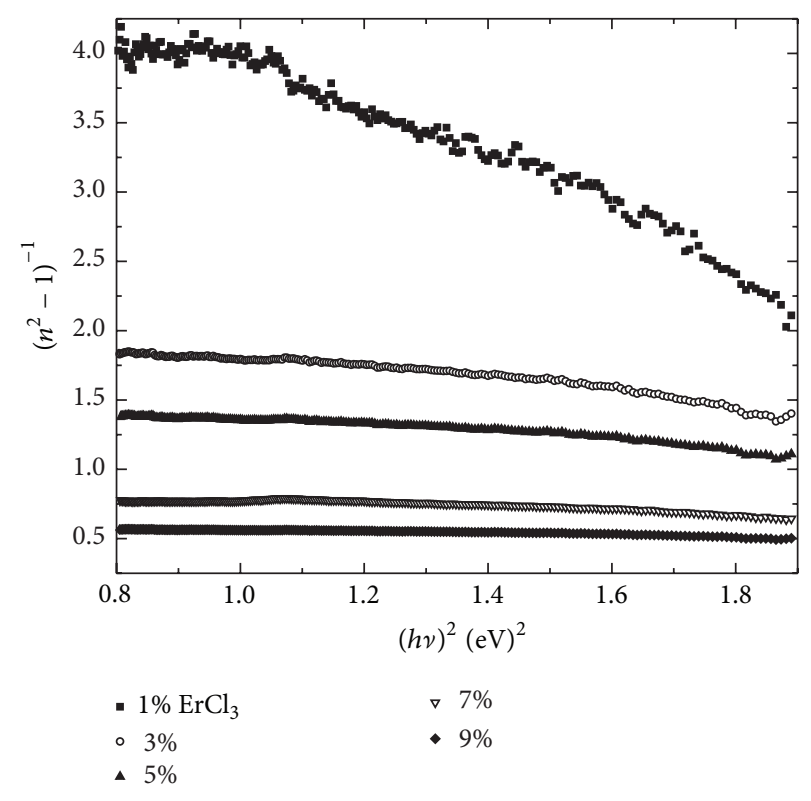

Figure 9: Variation between $\left(n^{2}-1\right)^{-1}$ and $(h v)^{2}$ in eV for PVA doped with different $\mathrm{ErCl}_{3}$ concentrations.

forming linking components for polymeric material and the multiple salt bridge results in the formation of a condensed structure.

The relation between $\left(n^{2}-1\right)^{-1}$ and $(h v)^{2}$ is displayed in Figure 9. Using (3), the slope of the linear part of this relation determines $E_{d}$, while the intercept with $y$-axis determines $E_{s}$. From Table 1 it is clear that the values of $E_{s}$ decrease with the increase in $\mathrm{ErCl}_{3}$ ratio within PVA structure. On the contrary, $E_{d}$ increases with the increase in $\mathrm{ErCl}_{3}$. Figure 10 shows that the relation between $\left(n^{2}-1\right)^{-1}$ and $\lambda^{-2}$ for PVA contains different concentrations of $\mathrm{ErCl}_{3}$ mentioned before. Using (5) and (6), we could calculate $n_{\infty}, \lambda_{o}$, and $S_{o}$, for each doped PVA sample. We expect that the results of this work will help 


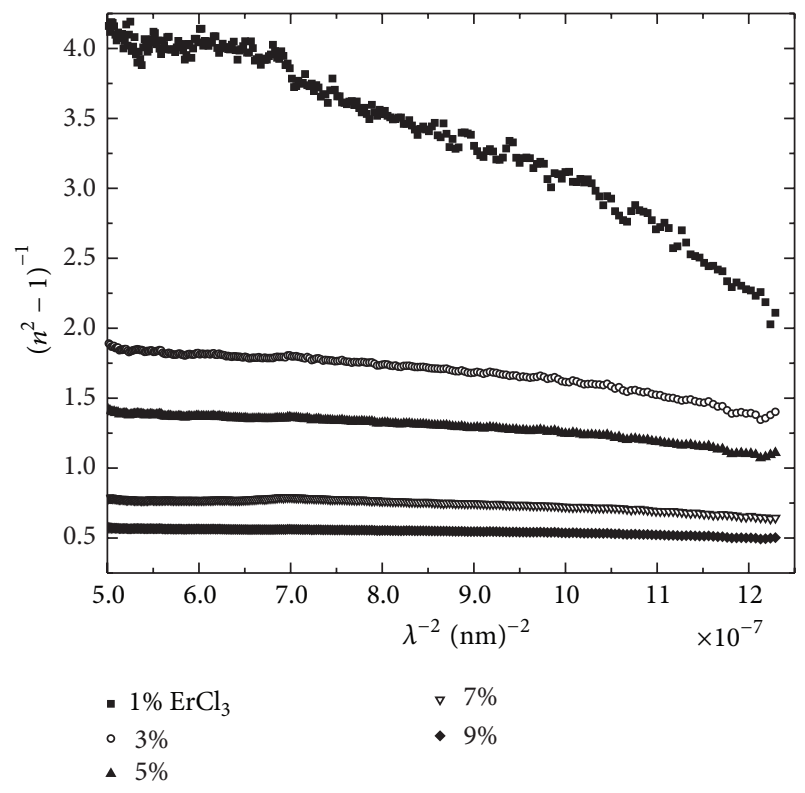

FIgURE 10: Variation between $\left(n^{2}-1\right)^{-1}$ and $\lambda^{2}$ in $\mathrm{nm}^{-2}$ for PVA doped with different concentrations of $\mathrm{ErCl}_{3}$.

the future research works in exploring the use of $\mathrm{ErCl}_{3}$ doped PVA for many optical applications.

\section{Conclusion}

The optical properties of PVA doped with different $\mathrm{ErCl}_{3}$ have been investigated. All doped PVA samples exhibit an apparent change in the optical transmittance and reflectance. The drastic change in the energy gap $E_{g}=0.5 \mathrm{eV}$ and the refractive index $n=1.72$ is achieved for PVA containing $9 \mathrm{wt} \%$ of $\mathrm{ErCl}_{3}$. This was attributed to the complexes formation between $\mathrm{Er}^{+3}$ ions and $\mathrm{OH}$ groups of PVA structure. The formation of complexes within PVA sample affects all optical parameters of the investigated sample. We have seen a drastic change in $E_{s}$ and $E_{d}$, due to the presence of $\mathrm{Er}^{+3}$ within PVA sample. PVA doped with 9 wt $\%$ of $\mathrm{ErCl}_{3}$ could be utilized as a new material for many optical applications.

\section{Conflict of Interests}

The authors declare that there is no conflict of interests regarding the publication of this paper.

\section{Acknowledgment}

The authors acknowledge Alexandria University for its financial support to publish this work.

\section{References}

[1] L. H. Slooff, A. van Blaaderen, A. Polman et al., "Rare-earth doped polymers for planar optical amplifiers," Journal of Applied Physics, vol. 91, no. 7, pp. 3955-3980, 2002.
[2] G. Kaur, Y. Dwivedi, and S. B. Rai, "Study of enhanced red emission from $\mathrm{Sm}(\mathrm{Sal})_{3}$ Phen ternary complexes in Poly Vinyl Alcohol film," Optics Communications, vol. 283, no. 18, pp. 34413447, 2010.

[3] M. C. Silva, A. S. S. de Camargo, L. A. D. O. Nunes, R. A. Silva, and A. Marletta, "Structural and spectroscopic characterization of poly(styrene sulfonate) films doped with neodymium ions," Journal of Non-Crystalline Solids, vol. 354, no. 52-54, pp. 5496$5503,2008$.

[4] D. Shao, L. Qin, and S. Sawyer, "Optical properties of polyvinyl alcohol (PVA) coated $\mathrm{In}_{2} \mathrm{O}_{3}$ nanoparticles," Optical Materials, vol. 35, no. 3, pp. 563-566, 2013.

[5] J. Messier, F. Kajzar, and P. N. Prasad, Organic Molecules for Nonlinear Optics and Photonics, Kluwer Academic, 1991.

[6] N. Kulshrestha, B. Chatterjee, and P. N. Gupta, "Characterization and electrical properties of polyvinyl alcohol based polymer electrolyte films doped with ammonium thiocyanate," Materials Science and Engineering B: Solid-State Materials for Advanced Technology, vol. 184, no. 1, pp. 49-57, 2014.

[7] L. Dalton, "Nonlinear optical polymeric materials: from chromophore design to commercial applications," in Polymers for Photonics Applications I, vol. 158 of Advances in Polymer Science, pp. 1-86, Springer, Berlin, Germany, 2002.

[8] S. A. Stepanchikova, R. P. Biteykina, and A. A. Sava, "An experimental study of hydrolytic behavior of thulium in basic and near-neutral solutions," Open Journal of Inorganic Chemistry, vol. 3, no. 2, pp. 42-47, 2013.

[9] Y. Dong, S. Hampshire, J.-E. Zhou, and G. Meng, "Synthesis and sintering of $\mathrm{Gd}$-doped $\mathrm{CeO}_{2}$ electrolytes with and without 1 at.\% $\mathrm{CuO}$ dopping for solid oxide fuel cell applications," International Journal of Hydrogen Energy, vol. 36, no. 8, pp. 5054-5066, 2011.

[10] L.-M. Zhao, X. Shao, Y.-B. Yin, and W.-Z. Li, "Binding of terbium complex to polymerizable hybrid materials constructed from molecular assembly and its optical properties," Materials Research Bulletin, vol. 44, no. 6, pp. 1334-1338, 2009.

[11] S. Moynihan, R. Van Deun, K. Binnemans et al., "Organolanthanide complexes as luminescent dopants in polymer waveguides fabricated by hot embossing," Optical Materials, vol. 29, no. 12, pp. 1798-1808, 2007.

[12] R. F. Bhajantri, V. Ravindrachary, A. Harisha, C. Ranganathaiah, and G. N. Kumaraswamy, "Effect of barium chloride doping on PVA microstructure: positron annihilation study," Applied Physics A: Materials Science and Processing, vol. 87, no. 4, pp. 797-805, 2007.

[13] M. Abdelaziz, "Cerium (III) doping effects on optical and thermal properties of PVA films," Physica B: Condensed Matter, vol. 406, no. 6-7, pp. 1300-1307, 2011.

[14] T. A. Hanafy, "Dielectric relaxation and alternating current conductivity of lanthanum, gadolinium, and erbium-polyvinyl alcohol doped films," Journal of Applied Physics, vol. 112, no. 3, Article ID 034102, 2012.

[15] J. Krstić, J. Spasojević, A. Radosavljević, M. Šiljegovć, and Z. Kačarević-Popović, "Optical and structural properties of radiolytically in situ synthesized silver nanoparticles stabilized by chitosan/poly(vinyl alcohol) blends," Radiation Physics and Chemistry, vol. 96, pp. 158-166, 2014.

[16] T. A. Hanafy, "Dielectric relaxation and alternating-current conductivity of gadolinium-doped poly(vinyl alcohol)," Journal of Applied Polymer Science, vol. 108, no. 4, pp. 2540-2549, 2008.

[17] T. A. Hamdalla and S. S. Nafee, "Experimental and theoretical studies for the gain of the neutron irradiated erbium doped fiber 
amplifier," Current Applied Physics, vol. 13, no. 6, pp. 981-984, 2013.

[18] L. H. Slooff, A. Polman, M. P. Oude Wolbers, F. C. J. M. Van Veggel, D. N. Reinhoudt, and J. W. Hofstraat, "Optical properties of erbium-doped organic polydentate cage complexes," Journal of Applied Physics, vol. 83, no. 1, pp. 497-503, 1998.

[19] N. M. Shah, J. R. Ray, K. J. Patel et al., "Structural, electrical, and optical properties of copper indium diselenide thin film prepared by thermal evaporation method," Thin Solid Films, vol. 517, no. 13, pp. 3639-3644, 2009.

[20] S. H. Wemple and M. DiDomenico, "Behavior of the electronic dielectric constant in covalent and ionic materials," Physical Review B, vol. 3, no. 4, pp. 1338-1351, 1971.

[21] A. E. Bekheet, N. A. Hegab, M. A. Afifi, H. E. Atyia, and E. R. Sharaf, "The effect of Ag addition on the optical properties of $\mathrm{Se}_{90} \mathrm{Te}_{10}$ films," Applied Surface Science, vol. 255, no. 8, pp. 45904594, 2009.

[22] B. Karthikeyan, "Novel synthesis and optical properties of $\mathrm{Sm}^{3+}$ doped Au- polyvinyl alcohol nanocomposite films," Chemical Physics Letters, vol. 432, no. 4-6, pp. 513-517, 2006.

[23] K. H. Mahmoud, Z. M. El-Bahy, and A. I. Hanafy, "Calorimetric, optical and catalytic activity studies of europium chloridepolyvinyl alcohol composite system," Journal of Physics and Chemistry of Solids, vol. 72, no. 9, pp. 1057-1065, 2011.

[24] S. Xu, Z. Yang, S. Dai, J. Yang, L. Hu, and Z. Jiang, "Spectral properties and thermal stability of $\mathrm{Er}^{3+}$-doped oxyfluoride silicate glasses for broadband optical amplifier," Journal of Alloys and Compounds, vol. 361, no. 1-2, pp. 313-319, 2003. 

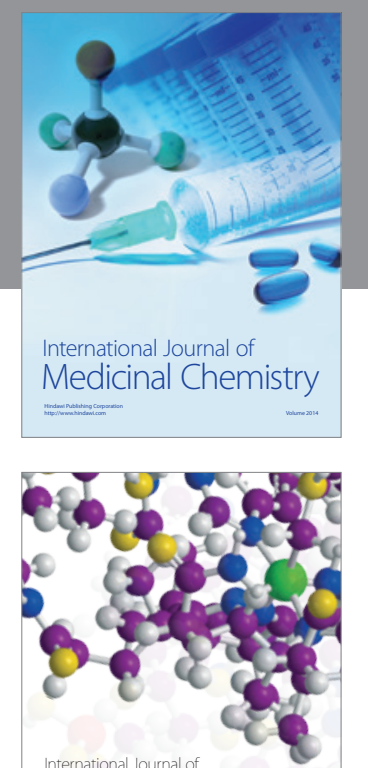

\section{Carbohydrate} Chemistry

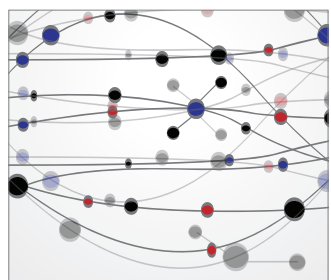

The Scientific World Journal
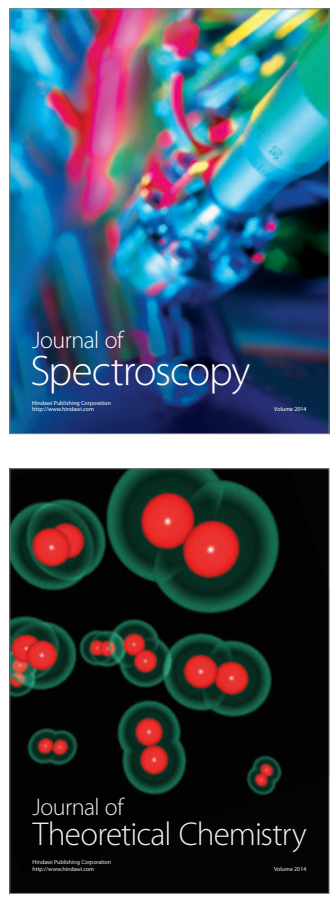
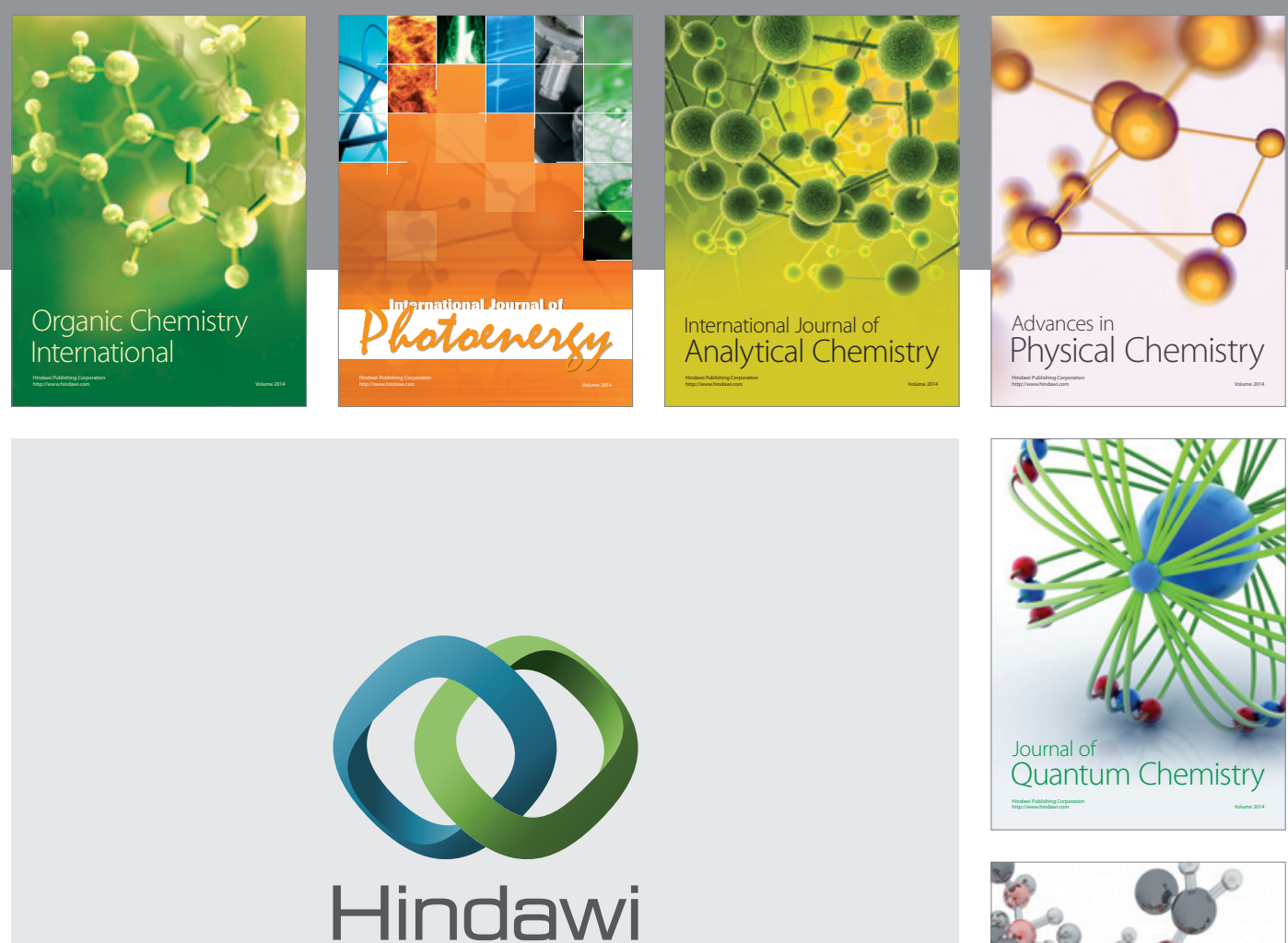

Submit your manuscripts at

http://www.hindawi.com

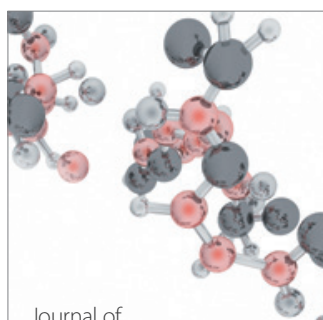

Analytical Methods

in Chemistry

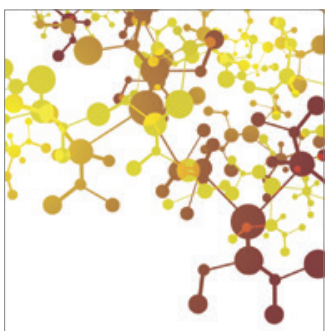

Journal of

Applied Chemistry

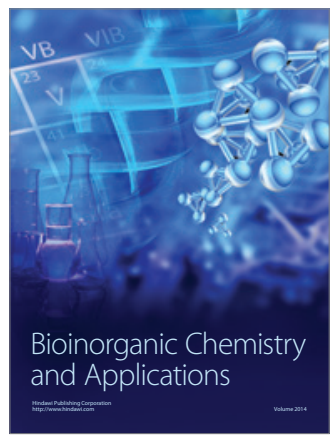

Inorganic Chemistry
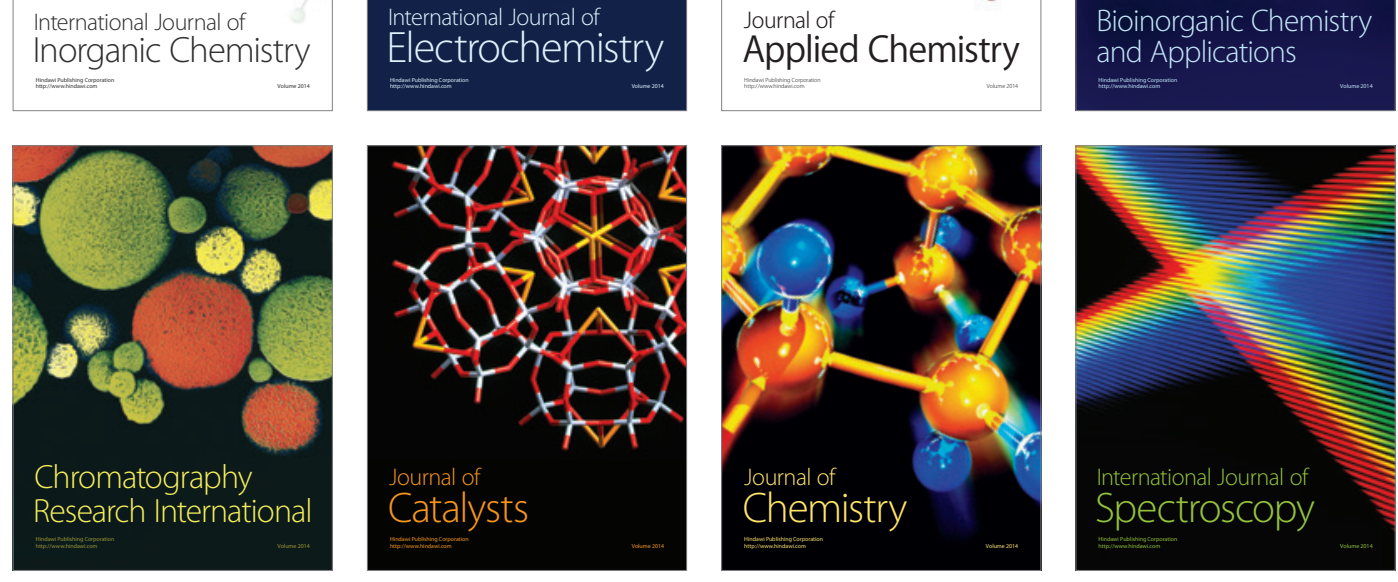